\title{
Longitudinal craze line propagation in human root dentin after instrumentation with NiTi rotary files of different instrument tapers after long-term chewing simulation
}

\author{
Marie-Therese Heberer ${ }^{1} \cdot$ Hubert C. Roggendorf $^{2} \cdot$ Franz-Josef Faber $^{3} \cdot$ Nicolai-Alexander Lawrenz $^{4}$. \\ Roland Frankenberger ${ }^{1} \cdot$ Matthias J. Roggendorf ${ }^{1}$
}

Received: 17 June 2021 / Accepted: 15 October 2021 / Published online: 17 November 2021

(c) The Author(s) 2021

\begin{abstract}
Objectives The aim of this study was to investigate whether file design and taper significantly influence microcrack initiation during machine preparation.

Materials and methods Sixty extracted teeth with straight single canals were selected. The teeth were randomly assigned to four groups based on their root canal anatomy and the corresponding NiTi rotary file system (I, Mtwo; II, ProTaper Universal; III, F6 SkyTaper; control, no preparation and filling). The root canals of the experimental groups were filled using the single-cone technique. The tested teeth were all subjected to a mechanical chewing simulation with flat lead loading over a period of 3 years (corresponding to 150,000 cycles). The teeth were checked for dentinal defects (accumulative crack growth in length) under the digital microscope (Keyence VHX-5000) at time 0 (baseline prior to chewing simulation) and after 3, 6, 12,24 , and 36 months of loading. The cumulative crack increase was statistically analyzed using the Kruskal-Wallis test, Jonckheere-Terpstra test, and the Wilcoxon rank-sum test. The significance was set at $p<0.05$.

Results In contrast to preparation with greater-tapered instruments, ProTaper Universal (group II) and F6 SkyTaper (group III) instrumentation with the smaller tapered Mtwo files (group I) showed less accumulative propagation of craze lines $(p<0.05)$ at all time points.

Conclusion Instruments with greater taper for root canal instrumentation should be used with care to avoid negative longterm effects in the form of propagation of dentinal defects over time. A positive cutting-edge angle and a smaller taper have a positive effect on a lower craze line development.

Clinical relevance Instruments with a positive cutting-edge angle and a smaller taper are beneficial for the long-term preservation of dentinal tooth structure.
\end{abstract}

Keywords Craze lines $\cdot$ Microcracks $\cdot$ Taper $\cdot$ Cutting-edge angle $\cdot$ Digital microscopy $\cdot$ Root dentin

Marie-Therese Heberer

heberer.med@gmx.de

1 Department of Operative Dentistry, Endodontics, and Pediatric Dentistry, Philipps University Marburg and University Hospital Giessen and Marburg, Campus Marburg, Georg-Voigt-Straße 3, 35039 Marburg, Germany

2 Interdisciplinary Department of Oral Surgery an Implantology, University of Cologne, Kerpener Straße 32, 50931 Cologne, Germany

3 Pre-Clinical Department, University of Cologne, Kerpener Straße 32, 50931 Cologne, Germany

4 Department of Mathematics and Computer Science, Philipps University of Marburg, Hans-Meerwein-Straße 6, 35043 Marburg, Germany

\section{Introduction}

Microcracks are defined as fine, incomplete craze lines that occur in areas of force concentration if the elastic limit of the tooth structure is exceeded, so they appear in most adults [1]. The propagation of microcracks may result in vertical root fractures (VRFs) which can potentially be a reason for extraction of the affected tooth [2-5]. Reasons for defects in dentine can be iatrogenic factors in the course of endodontic treatment, such as the opening of the tooth through a central access cavity, instrumentation [6,7], the irrigation protocol used [8, 9], the medicinal insertion [10], or the filling technique [11-13]. When instrumenting a root canal, the canal wall is always exposed to forces by instrumentation and may be damaged, 
which can potentially result in the propagation to incomplete or complete fractures $[13,14]$. The instrument design and the number of files used have been shown to affect the probability of microcracks developing in the radicular dentin $[5,6$, 15-17]. However, the influence of endodontic treatment on microcrack formation is highly controversial. Some authors assume that the microcracks observed in the aforementioned studies are much more a consequence of the extraction process in in vitro studies $[18,19]$. The microcrack formation is said to be independent of the extraction technique but a consequence of the dehydration process outside the oral cavity [19, 20]. In this way, the methodology of the earlier mentioned studies is questioned [19].

In this study, three different instrument systems were used. Mtwo (VDW GmbH, Munich, Germany) was the first system developed for fully-rotating instrumentation of root canals using the single-length technique. An advantage here is the guiding function of the non-cutting instrument tip for good centering in particularly curved canals. As soon as one instrument reaches full working length, the operator can switch to the next file size [14, 21-24]. The ProTaper Universal system (Dentsply Sirona GmbH, Bensheim, Germany) combines different tapers within one instrument as expressed by the name $($ Pro $=$ progressive, Taper $=$ instrument taper $)$. After preparation of the access cavity, the canal entrance is enlarged by the shaping files SX, S1, and S2, followed by the instrumentation of the apical canal portions with finishing files from F1 to F4 depending on the root canal anatomy. The instrumentation is performed using a crown-down preparation [14, 25]. The third system used in this study is the single-file system F6 SkyTaper (Komet Dental GmbH \& Co. KG, Lemgo, Germany). The manufacturer advertises the high flexibility of these files. The canal preparation should be performed using three in-and-out movements, cleaning of the instruments, followed by intermittent irrigation of the root canal [26, 27]. Instrumentation is finished when the instrument reaches working length without binding to the canal wall.

The present study investigates whether craze line propagation can be related to endodontic treatment. For this purpose, the methodology was checked in advance using in a preliminary test. If a relation can be shown, the influence of instrument taper, cutting-edge angle, number of files, and design (reverse vs. continuous taper) on the formation and increase of craze lines in root dentin will be investigated. The null hypothesis was that the instrument design has no significant influence on craze line formation.

\section{Materials and methods}

Prior to the start of the main experiment, a pre-group $(n=15)$ was selected and pre-treated in the same way for a preliminary proof to confirm the methodology used. The aim was to analyze the effect of repeated drying on crack development. For this purpose, twelve digital microscope images were taken of each tooth, and the crack increase was analyzed. The teeth were only dried for the exposures and otherwise stored wet.

The sample size was calculated a priori using the software $R$ (R Foundation for Statistical Computing, Vienna, Austria) performed by a chi-square power test (with $\alpha=0.05, \beta=0.95$ ) [28]. A predefined power of 0.9 resulted in a sample size of 15 teeth per group as the required target value. Therefore, we used a total sample size of 60 teeth $(n=15)$.

Figure 1 shows the experimental procedure of the main trial. Throughout the study, all teeth were stored in $0.9 \%$ isotonic $\mathrm{NaCl}$ solution with $0.001 \%$ sodium azide. The root canal preparation of the different experimental groups (see Table 1 and Fig. 1) was carried out with the torque-limited endomotor EndoPilotl (Schlumbohm GmbH \& Co. KG, Brokstedt, Germany). All instruments were used according to the manufacturer instruction. The simulation of periodontal tissue was performed by the use of the thin-flowing type A-silicone Correct flow (Kulzer GmbH, Hanau, Germany) as it was realized in several other studies [35]. During instrumentation of the teeth, the root canals were filled with $\mathrm{NaOCl} 3 \%$, and irrigation was unable to disappear due to the embedding in the molds.

Before starting the chewing simulation (baseline), the teeth were examined for microcracks from both contralateral sides with digital microscopic scans (Keyence VHX-5000, lens: Keyence VH-Z20T, Keyence Corp., Osaka, Japan) (magnification: $200 \times$, step $\mathrm{z}=20 \mu \mathrm{m}$ ). For this purpose, the molds were individually prepared for each tooth so that each scan could be made from exactly the same position mesially and distally. Repeated scans after 12,500 and 25,000 chewing cycles (representing a masticatory load over 3,6 , 12,24 , and 36 months) enabled subsequent software-based measurement of the crack growth in number and length using Adobe Illustrator (Adobe Inc., San José, CA, USA). The images were superimposed, and the crack growths were color-coded and measured afterwards (see Fig. 2). In this way, 12 scans per tooth were taken for precise crack analysis to record the crack propagation over the observation period.

The statistical evaluation was also performed with the statistical software $R$ (R Foundation for Statistical Computing, Vienna, Austria). First, the Kolmogorov-Smirnov test was used to examine whether the collected data corresponded to a normal distribution. Since there was no normal distribution of the values in this study, the evaluation of the null hypothesis was carried out exclusively with non-parametric test procedures [36]. The Kruskal-Wallis test was computed to calculate if there were any differences in terms of propagation of dentinal defects between the experimental groups. The Jonckheere-Terpstra test and Wilcoxon rank-sum test 
Single rooted teeth assessed for eligibility (117)

60 teeth were cleaned, freed from root cement and divided into four groups based on the conicity of the root canal (measured on radiographs) to guarantee a complete endodontic treatment (see table 1)

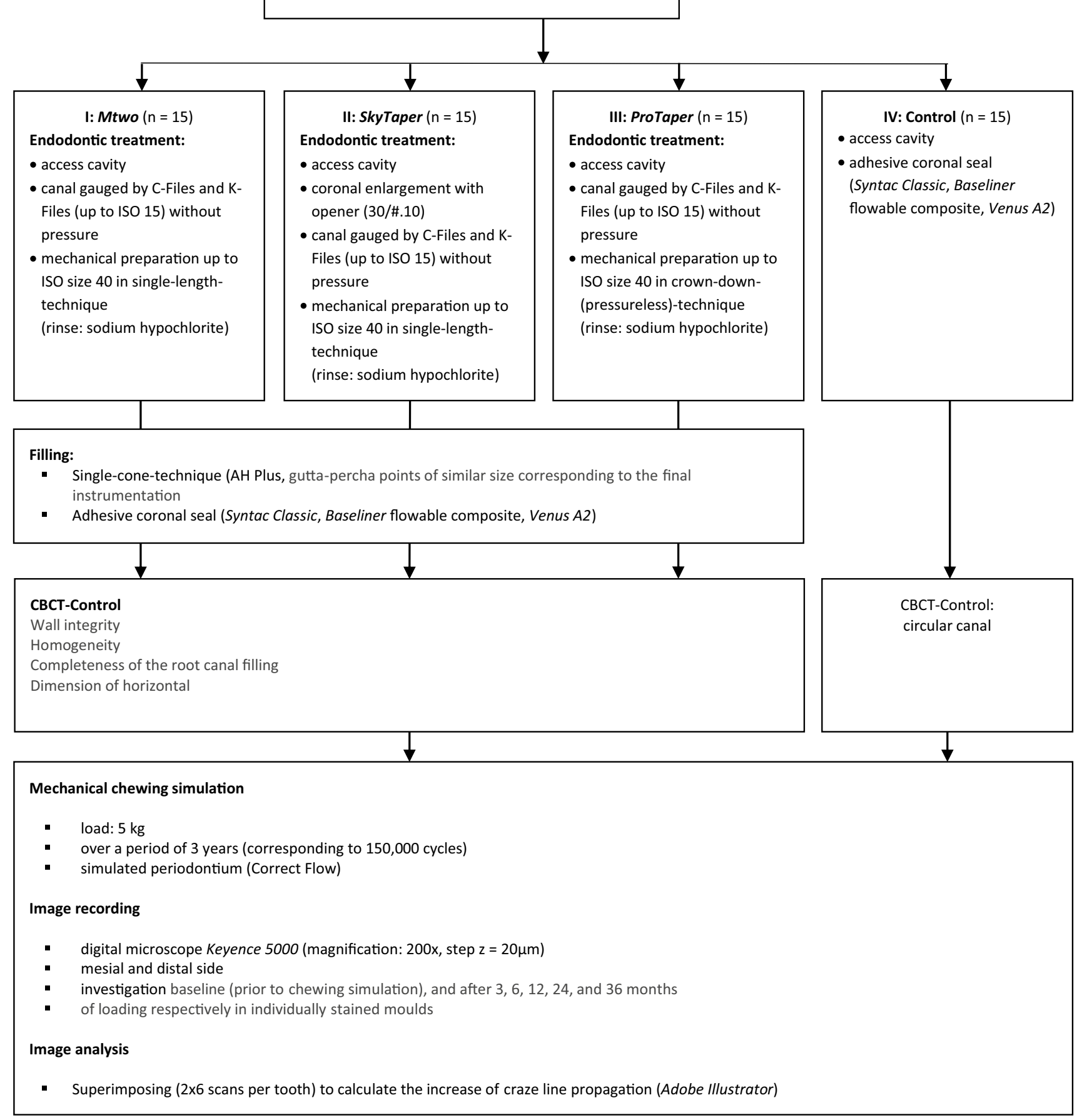

Fig. 1 The experimental procedure of the main trial 
Table 1 Overview of the experimental groups [17, 27, 29-34]

\begin{tabular}{|c|c|c|c|c|c|c|}
\hline Group & File system & File sequences & Manufacturer & Taper & Cross-section & Technique \\
\hline I & Mtwo & $\begin{array}{l}\# 10 / .04, \# 15 / .05 \\
\# 20 / .06, \# 25 / .05, \\
\# 30 / .06, \# 35 / .04, \\
\# 40 / .04\end{array}$ & $\begin{array}{l}\text { VDW Dental, } \\
\text { Munich, Germany }\end{array}$ & Continuous taper .04 & $\begin{array}{l}\text { S-shaped (active } \\
\text { cutting) with a } \\
\text { large chip space } \\
\text { and small core } \\
\text { diameter }\end{array}$ & $\begin{array}{l}\text { Single-length (full } \\
\text { rotation) }\end{array}$ \\
\hline II & SkyTaper F6 & $\begin{array}{l}\text { Opener \#30/.10, } \\
\text { \#40/.06 }\end{array}$ & $\begin{array}{l}\text { Komet Dental, } \\
\text { Lemgo, Germany }\end{array}$ & Continuous taper .06 & $\begin{array}{l}\text { Double-S-shaped } \\
\text { (active cutting) } \\
\text { with a large chip } \\
\text { space and small } \\
\text { core diameter }\end{array}$ & $\begin{array}{l}\text { Single-length (full } \\
\text { rotation) }\end{array}$ \\
\hline III & $\begin{array}{l}\text { ProTaper Universal } \\
\quad \text { F4 }\end{array}$ & $\begin{array}{l}\mathrm{SX}, \mathrm{S} 1, \mathrm{~S} 2, \mathrm{~F} 1 \\
(\# 20 / .07), \mathrm{F} 2 \\
(\# 25 / .08), \mathrm{F} 3 \\
(\# 30 / .09), \mathrm{F} 4 \\
(\# 40 / .06)\end{array}$ & $\begin{array}{l}\text { Dentsply Sirona, } \\
\text { Bensheim, Ger- } \\
\text { many }\end{array}$ & $\begin{array}{l}\text { Reverse taper .06 } \\
\text { (different progres- } \\
\text { sive tapers from } \\
2 \% \text { up to } 11.5 \% \text { ) }\end{array}$ & $\begin{array}{l}\text { Up to F3: slightly } \\
\text { convex triangular } \\
\text { (passive-cutting), } \\
\text { F4 concave }\end{array}$ & $\begin{array}{l}\text { Crown-down } \\
\text { (pressure-less) } \\
\text { technique (full } \\
\text { rotation) }\end{array}$ \\
\hline IV & \multicolumn{2}{|c|}{$\begin{array}{l}\text { Occlusal cavity, composite filling, no } \\
\text { preparation and filling }\end{array}$} & -- & -- & -- & -- \\
\hline Control & \multicolumn{2}{|c|}{$\begin{array}{l}\text { No treatment, no chewing simulation, only } \\
\text { digital microscopic scans }\end{array}$} & -- & -- & -- & -- \\
\hline
\end{tabular}

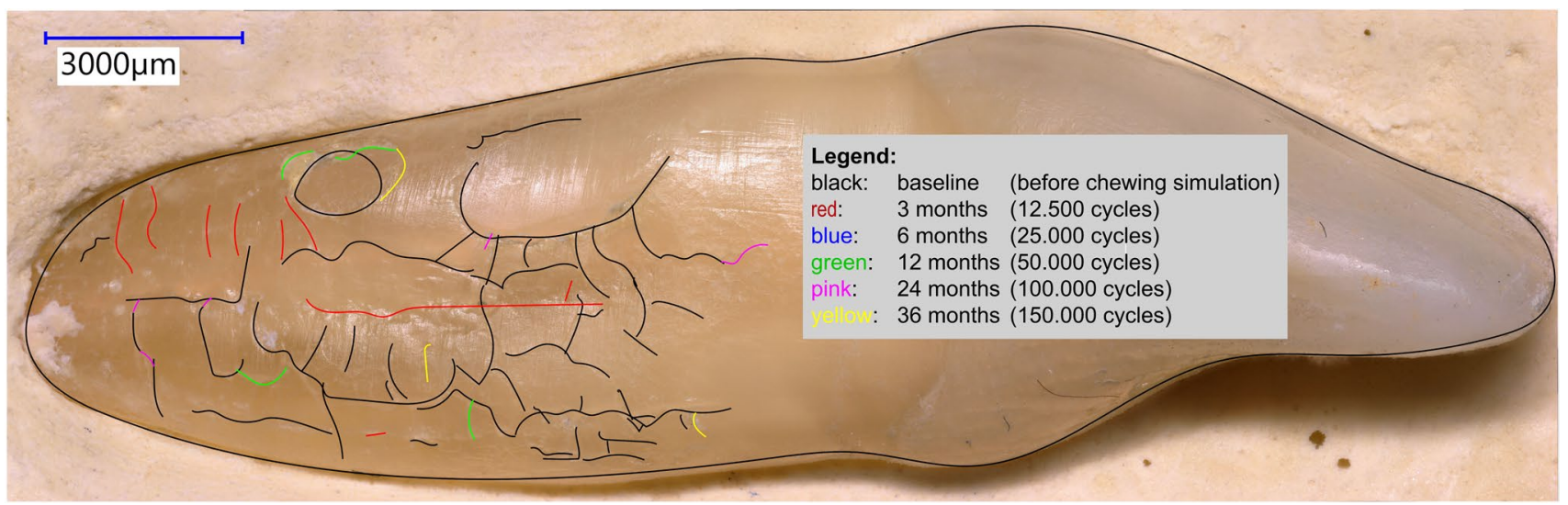

Fig. 2 Before starting the chewing simulation (baseline), the teeth were examined for microcracks from both contralateral sides with digital microscopic scans (Keyence VHX-5000, lens: Keyence VH-

were used to evaluate the crack increases between the groups [37].

\section{Results}

The pre-trial group did not show any crack increase at any time ( $0 \mu \mathrm{m}=$ no accumulative crack increase). Figure 3 gives an overview of craze line propagation over the observation period of 3 years starting from baseline $[\mu \mathrm{m}]$. The Kruskal-Wallis test confirmed that there were clear differences in crack growth between the groups. The Jonckheere-Terpstra test showed that Mtwo led to less cumulative crack growth than the other two groups at all observation points $(p<0.5)$. According to
Z20T, Keyence Corp., Osaka, Japan) (magnification: $200 \times$, step $\mathrm{z}=20 \mu \mathrm{m})$. The images were superimposed, and the crack growths were color-coded and measured afterwards

the pairwise comparisons with the Wilcoxon rank-sum test, the results were only significant for the comparison of Mtwo with SkyTaper up to 24 months $(p<0.05)$. ProTaper Universal tended to perform better than SkyTaper up to 24 months $(p<0.5)$. However, at 36 months, ProTaper showed little higher craze line propagation compared to SkyTaper. Even the control group showed a moderate increase between 2 and 3 years. 
Fig. 3 An overview of craze line propagation over the observation period of 3 years starting from baseline $[\mu \mathrm{m}]$

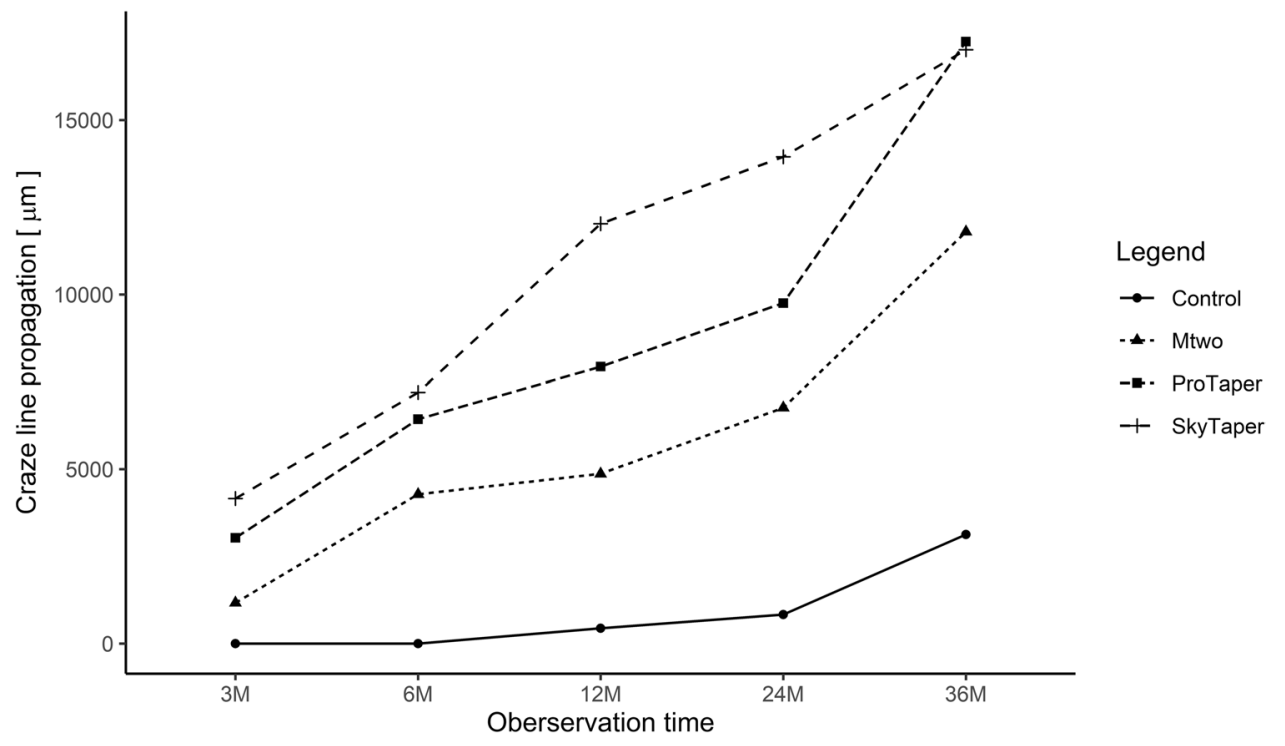

\section{Discussion}

The current study investigated the occurrence of superficial dentinal craze lines, a type of microcracks that can be detected on the root surface after endodontic therapy. A correlation between the preparation systems used and the increase in craze lines was observed, rejecting the null hypothesis. The methodology used was confirmed by the pre-trial: as there was no propagation of craze lines observed due to the short dry storage mandatory during the scanning process by digital microscopy can be excluded as falsification. As shown by a $\mu \mathrm{CT}$ study of Rödig et al., prolonged dehydration up to $24 \mathrm{~h}$ does not result in the generation of new dentinal cracks [38] although this effect was detected by means of a $\mu \mathrm{CT}$. In the uninstrumented control group (IV, filling only), almost no increase in terms of total craze line propagation was observed (as in other studies) [16, 39, 40]. The slight increase in craze lines was related to the chewing load and the use of human samples. Due to the use of human tooth samples, these were exposed to different stresses and environmental influences before the start of the study, which represents an influencing factor on crack formation. One explanation can be found in natural tooth aging, which leads to changes in the dentin collagen structure as well as a reduced water content and a reduction in bending and fracture strength as well as flexibility [41-44]. Additionally, it should not be neglected that the extraction process also generates forces that may have an impact on the teeth [45]. A correlation for the occurrence of microcracks post extractionem with the patients' age could also be found [45]. De-Deus' statement postulated that microcracks must be regarded as a trial-related phenomenon cannot be accepted based on the results of the present study [19, 20, 46]. No VRF occurred in any test group in the present study.
At present, no study has investigated the increase of cracks in freshly treated endodontic teeth in a long-term chewing simulation over several years. For the repeated investigation of the development of craze lines, a digital microscopic analysis of superficial dentinal defects in the form of craze lines was chosen. Optical microscopy of root surfaces and apices has so far only been used to visualize apical crack growth [15, 47-50]. Several studies on dentinal defects after root canal treatment were carried out by microscopy by horizontal sectioning of the roots $[6,13,14$, $35,39,40,51,52]$, which have shown to result in an increase in crack formation [53-55]. Although the depth of the cracks can be assessed adequately by this method, no progress control is possible during masticatory loading. However, it was shown that the destructive method of horizontal sectioning resulted in a higher number of dentinal defects when compared with the non-destructive $\mu \mathrm{CT}$ analysis [56]. Digital microscopy is well-suited for imaging microcracks. Depending on the resolution, it is indeed possible that not all present craze lines will be detected $[57,58]$. In a study using nonobturated teeth, no significant differences between $\mu \mathrm{CT}$ and stereo-microscopic analysis for the detection of craze lines were detected. The scanning electron microscope detected significantly more craze lines in this analysis, whereas the detectability using CBCT revealed significantly less craze lines [56]. In the present study, electron microscopy was not chosen due to the inability of the SEM technique to allow repeated scans of the specimens. SEM investigation requires a drying process followed by a sputtering of the samples. These pretreatment steps do not allow a repeated chewing simulation. Additionally, repeated vacuuming and increased drying probably would have induced more craze lines [59]. An alternative use of the replica technique for repeated SEM scans would be more than questionable in terms of the 
reproduction of craze lines because the impression material needs to penetrate cracks in order to allow their detection [60]. Another imaging technique that was repeatedly used in several studies was the $\mu \mathrm{CT}$. However, this technique was not chosen because the presence of a root canal filling, as classic dental film or CBCT, makes the diagnosis of VRFs more difficult [48]. This can be transferred to the smaller craze lines. Furthermore, Rödig et al. have shown that the moisture content of the specimens is crucial in terms of the detectability of cracks when using the $\mu \mathrm{CT}$ [38]. The results showed that the $\mu \mathrm{CT}$ scans should be performed on dry specimens. Regarding the existing $\mu \mathrm{CT}$, no information was given on the moisture content of the specimens during the scanning process. Thus, the conclusion that no differences in terms of crack were found in these studies could be questioned. Another aspect that complicates the analysis of small structures such as microcracks in the dentin in $\mu \mathrm{CT}$ images are related to artifacts such as the beam hardening effect caused by obturation materials [61-63]. By using artifact reduction tools such as a copper filter, the beam hardening effect can be reduced, but it cannot be completely eliminated and may lead to a reduction in image quality $[61,64,65]$. Queiroz et al. were able to show that the use of such tools had no influence on the results of the findings, but only subjectively facilitates the analysis [61]. Therefore, we decided to include high magnifications using the digital microscope in order to include color differences and variations in opacity and transparency for a sufficient detection of craze lines.

The results of the main experiment show that smaller tapered instruments represented by the Mtwo system caused less craze line propagation than the other two systems at all time points $(p<0.05)$. This is consistent with another paper that compares the craze line incidence of Mtwo with ProTaper Universal [40]. This can be attributed to the increased cutting performance of Mtwo due to its instrument geometry. The triangular cross-section of ProTaper results in less space for dentine chips and a smaller cutting efficiency, which, in addition to a lower cleanability [29, 40], also leads to an increase in torque [66, 67]. An additional torque increase occurs due to its greater taper, leading to greater applied vertical force in the apical direction with increasing preparation depth. Thus, additional stress on the dentin and significantly more cracks occur [66, 67]. Significantly more craze line initiation has been detected by using ProTaper in high-torque setting [30]. In the present study, a torque-controlled motor was used, which precluded exceeding the maximum torque recommended by the manufacturers. The EndoPilot1 (Schlumbohm, Brokstedt, Germany) shows good results with regard to its torque limitation [67]. Studies comparing initial instrumentation and retreatment showed that greater manipulation in the apical third of the root canal interior leads to an increase in cracks $[6,52]$. In this study, this can be transferred to the comparison of the active cutting system Mtwo with its lower wedging effect by the use of the passive-cutting ProTaper Universal. The high craze line incidence of ProTaper Universal is in line with several other studies $[6,14,15,25,47,68,69]$. At present, PubMed does not list any studies that compare the incidence of craze lines development of F6 SkyTaper (taper.06, constant taper) with one of the other two systems (August 2021). In this investigation, F6 SkyTaper performed significantly worse than Mtwo (up to 24 months) but similar to ProTaper Universal. The explanation can be found in the greater file taper. However, the file cross-section is different and rather comparable to that of Mtwo and even performed better in studies regarding cutting efficiency, although not significant [31]. In addition to the good cleaning performance, this can be seen as a positive factor in favor of low craze line formation. However, Pedullà et al. found the instrument geometry in this context to be only a co-factor and place the instrument flexibility due to different alloys at the center of the reasons for the crack increases [17]. As the alloys from the different manufacturers used in the present study were very similar and moreover not thermally modified to reduce their rigidity $[17,25,70]$, this statement can be applied to differences in flexibility due to different core diameters. The core diameter increases proportionally with the taper of the instrument. This is another explanation for the lower increase of crack length of the less-tapered Mtwo in the comparison with the other two systems. Regarding the fact that the F6 SkyTaper is designed as a single-file system, which has the advantage in the reduction of the number of instruments and a shorter working time, those instruments generally revealed a higher incidence of cracking already in other studies [17, 71].

It was surprising that the multifile-system ProTaper Universal with a reverse taper did not show superior results in comparison to F6 SkyTaper with a constant taper over 36 months. This is in contrast to findings in current literature showing multifile-systems generating lower initial stress and forces applied to the dentinal walls [71-73]. Although a reduction of the load for every single file would be expected, an addition of all files used results in a greater manipulation and potentially a subsequent accumulation of dentinal damage [47]. So this result is quite pleasing for the practitioner due to significant time savings when using a single-file system [29]. Liu et al. compared three single-file systems with ProTaper Universal in their 2013 study and found contrasting results [47]. One possible explanation for the comparable results of F6 SkyTaper and ProTaper in terms of craze line propagation in the present study was that sufficient coronal access was already created by means of the Opener file in favor of the F6. In addition, the root canal was gauged using $\mathrm{C}$-files prior to mechanical preparation and a glide paths with ISO size $15 \mathrm{~K}$-files. This step may have optimized the instrumentation resulting in less forces. Another factor in this comparison may be related to the instrument design. 
ProTaper Universal with its triangular cross-section is a passive-cutting system, that shows less cutting efficiency and a smaller chip space for the removal of dentin chips, and consequently leads to stress in the inner root canal walls [29]. In contrast, F6 SkyTaper showed very good results in terms of cutting performance [31].

\section{Conclusion}

A positive cutting-edge angle and a smaller instrument taper have a positive effect on the time-dependent craze line development. Microcracks may serve as a precursor of VRFs. Therefore, reduced instrumentation stress may preserve the tooth structure over time.

Author contribution All authors contributed to the study conception and design. Material preparation, data collection, and analysis were performed by Marie-Therese Heberer, PD Dr. Matthias J. Roggendorf, Dr. Hubert C. Roggendorf, and Nicolai-Alexander Lawrenz. The first draft of the manuscript was written by Marie-Therese Heberer, and all authors commented on previous versions of the manuscript. All authors read and approved the final manuscript.

Funding Open Access funding enabled and organized by Projekt DEAL. PhD Scholarship for Marie-Therese Heberer (von-Behring-Röntgen-Stiftung).

\section{Declarations}

Ethics approval This article does not contain any studies with human participants or animals performed by any of the authors.

Consent to participate This study was done on teeth that were selected from a random collection of human teeth, which were extracted for various reasons, not related to this study. Thus, for this type of study, formal consent is not required.

Conflict of interest The authors declare no competing interests.

Open Access This article is licensed under a Creative Commons Attribution 4.0 International License, which permits use, sharing, adaptation, distribution and reproduction in any medium or format, as long as you give appropriate credit to the original author(s) and the source, provide a link to the Creative Commons licence, and indicate if changes were made. The images or other third party material in this article are included in the article's Creative Commons licence, unless indicated otherwise in a credit line to the material. If material is not included in the article's Creative Commons licence and your intended use is not permitted by statutory regulation or exceeds the permitted use, you will need to obtain permission directly from the copyright holder. To view a copy of this licence, visit http://creativecommons.org/licenses/by/4.0/.

\section{References}

1. Rivera EM, Walton RE (2007) Longitudinal tooth fractures: findings that contribute to complex endodontic diagnoses. Endod Top $16: 82-111$

2. Wilcox LR, Roskelley C, Sutton T (1997) The relationship of root canal enlargement to finger-spreader induced vertical root fracture. J Endod 23:533-534

3. Lertchirakarn V, Palamara JE, Messer HH (1999) Load and strain during lateral condensation and vertical root fracture. J Endod 25:99-104

4. Campello AF, Marceliano-Alves MF, Siqueira JF, Fonseca SC, Lopes RT, Alves FR (2021) Unprepared surface areas, accumulated hard tissue debris, and dentinal crack formation after preparation using reciprocating or rotary instruments: a study in human cadavers. Clin Oral Investig 25:1-10

5. Jamleh A, Nassar M, Alfadley A, Khan S, Alfouzan K, Adorno C (2021) Influence of additional apical enlargement on microcrack formation in root dentine: a micro-computed tomography investigation. Clin Oral Investig 25:1-7

6. Bier CAS, Shemesh H, Tanomaru-Filho M, Wesselink PR, Wu M-K (2009) The ability of different nickel-titanium rotary instruments to induce dentinal damage during canal preparation. J Endod 35:236-238

7. Tamse A (2008) Vertical root fracture of endodontically treated teeth. BC Decker Inc., Toronto

8. Sim T, Knowles J, Ng YL, Shelton J, Gulabivala K (2001) Effect of sodium hypochlorite on mechanical properties of dentine and tooth surface strain. Int Endod J 34:120-132

9. Braun A, Hagelauer FJ-P, Wenzler J, Heimer M, Frankenberger R, Stein S (2018) Microcrack analysis of dental hard tissue after root canal irradiation with a $970-n m$ diode laser. Photomed Laser Surg 36:621-628

10. Yassen G, Vail M, Chu T, Platt J (2013) The effect of medicaments used in endodontic regeneration on root fracture and microhardness of radicular dentine. Int Endod J 46:688-695

11. Onnink PA, Davis RD, Wayman BE (1994) An in vitro comparison of incomplete root fractures associated with three obturation techniques. J Endod 20:32-37

12. Meister F Jr, Lommel TJ, Gerstein H (1980) Diagnosis and possible causes of vertical root fractures. Oral Surg Oral Med Oral Pathol Oral Radiol 49:243-253

13. Shemesh H, Bier C, Wu MK, Tanomaru-Filho M, Wesselink P (2009) The effects of canal preparation and filling on the incidence of dentinal defects. Int Endod J 42:208-213

14. Hin ES, Wu M-K, Wesselink PR, Shemesh H (2013) Effects of self-adjusting file, Mtwo, and ProTaper on the root canal wall. J Endod 39:262-264

15. Liu R, Kaiwar A, Shemesh H, Wesselink PR, Hou B, Wu M-K (2013) Incidence of apical root cracks and apical dentinal detachments after canal preparation with hand and rotary files at different instrumentation lengths. J Endod 39:129-132

16. Yoldas O, Yilmaz S, Atakan G, Kuden C, Kasan Z (2012) Dentinal microcrack formation during root canal preparations by different NiTi rotary instruments and the self-adjusting file. $\mathbf{J}$ Endod 38:232-235

17. Pedullà E, Genovesi F, Rapisarda S, La Rosa GRM, Grande NM, Plotino G, Adorno CG (2017) Effects of 6 single-file systems on dentinal crack formation. J Endod 43:456-461

18. Arashiro FN, De-Deus G, Belladonna FG, Cavalcante DM, Coelho MS, Silva E, Pereira KFS, da Silva PG, Lopes RT, Souza EM (2020) Dentinal microcracks on freshly extracted teeth: the impact of the extraction technique. Int Endod J 53:440-446

19. De-Deus G, Cavalcante DM, Belladonna FG, Carvalhal J, Souza EM, Lopes RT, Versiani MA, Silva EJNL, Dummer PMH 
(2019) Root dentinal microcracks: a post-extraction experimental phenomenon? Int Endod J 52:857-865

20. De-Deus G, Silva EJ, Marins J, Souza E, Neves Ade A, Gonçalves Belladonna F, Alves H, Lopes RT, Versiani MA (2014) Lack of causal relationship between dentinal microcracks and root canal preparation with reciprocation systems. J Endod 40:1447-1450

21. Schäfer E, Erler M, Dammaschke T (2006) Comparative study on the shaping ability and cleaning efficiency of rotary Mtwo instruments. Part 1 . Shaping ability in simulated curved canals. Int Endod J 39:196-202

22. Schäfer E, Erler M, Dammaschke T (2006) Comparative study on the shaping ability and cleaning efficiency of rotary Mtwo instruments. Part 2. Cleaning effectiveness and shaping ability in severely curved root canals of extracted teeth. Int Endod J 39:203-212

23. Roggendorf MJ, Frankenberger R (2012) Maschinelle nickeltitan-systeme im überblick. Quintessenz Zahnmedizin 63:1-7

24. Roggendorf MJ, Ebert J, Frankenberger R (2015) Aktuelle entwicklungen der maschinellen wurzelkanalaufbereitung. Zahnmedizin Update 9:393-420

25. Capar ID, Arslan H, Akcay M, Uysal B (2014) Effects of ProTaper Universal, ProTaper Next, and HyFlex instruments on crack formation in dentin. J Endod 40:1482-1484

26. Donnermeyer D, Viedenz A, Schäfer E, Bürklein S (2020) Impact of new cross-sectional designs on the shaping ability of rotary NiTi instruments in S-shaped canals. Odontology 108:174-179

27. Bürklein S, Jäger PG, Schäfer E (2017) Apical transportation and canal straightening with different continuously tapered rotary file systems in severely curved root canals: F6 SkyTaper and OneShape versus Mtwo. Int Endod J 50:983-990

28. Champely S (2020) pwr: basic functions for power analysis. $R$ package version 1.3-0. 2020. URL https://CRANR-project.org/ package $=$ pwr

29. Bürklein S, Hinschitza K, Dammaschke T, Schäfer E (2012) Shaping ability and cleaning effectiveness of two single-file systems in severely curved root canals of extracted teeth: Reciproc and WaveOne versus Mtwo and ProTaper. Int Endod J 45:449-461

30. Dane A, Capar ID, Arslan H, Akçay M, Uysal B (2016) Effect of different torque settings on crack formation in root dentin. J Endod 42:304-306

31. Kar PP, Khasnis SA, Kidiyoor KH (2017) Comparative evaluation of cleaning efficacy using four novel nickel-titanium rotary instruments: an in vitro scanning electron microscope study. J Contemp Dent Pract 18:1135-1143

32. Dagna A, Gastaldo G, Beltrami R, Chiesa M, Poggio C (2016) F360 and F6 Skytaper: SEM evaluation of cleaning efficiency. Ann Stomatol (Roma) 6:69-74

33. Jindal R, Singh S, Gupta S, Jindal P (2012) Comparative evaluation of apical extrusion of debris and irrigant with three rotary instruments using crown down technique - an in vitro study. J Oral Biol Craniofac Res 2:105-109

34. Bergmans L, Van Cleynenbreugel J, Beullens M, Wevers M, Van Meerbeek B, Lambrechts P (2002) Smooth flexible versus active tapered shaft design using NiTi rotary instruments. Int Endod J $35: 820-828$

35. Kfir A, Elkes D, Pawar A, Weissman A, Tsesis I (2017) Incidence of microcracks in maxillary first premolars after instrumentation with three different mechanized file systems: a comparative ex vivo study. Clin Oral Investig 21:405-411

36. Weiß C (2007) Basiswissen medizinische statistik. Springer-Verlag

37. Wasserstein RL, Lazar NA (2016) The ASA statement on p-values: context, process, and purpose. Am Stat 70:129-133

38. Rödig T, Müller C, Hoch M, Haupt F, Schulz X, Wiegand A, Rizk M (2018) Moisture content of root canal dentine affects detection of microcracks using micro-computed tomography. Int Endod J 51:357-363

39. Barreto MS, Moraes RdA, da Rosa RA, Moreira CHC, Só MVR, Bier CAS (2012) Vertical root fractures and dentin defects: effects of root canal preparation, filling, and mechanical cycling. J Endod 38:1135-1139

40. Bürklein S, Tsotsis P, Schäfer E (2013) Incidence of dentinal defects after root canal preparation: reciprocating versus rotary instrumentation. J Endod 39:501-504

41. Shinno Y, Ishimoto T, Saito M, Uemura R, Arino M, Marumo K, Nakano T, Hayashi M (2016) Comprehensive analyses of how tubule occlusion and advanced glycation end-products diminish strength of aged dentin. Sci Rep 6:19849

42. Miura J, Nishikawa K, Kubo M, Fukushima S, Hashimoto M, Takeshige F, Araki T (2014) Accumulation of advanced glycation end-products in human dentine. Arch Oral Biol 59:119-124

43. Tonami K, Takahashi $\mathrm{H}$ (1997) Effects of aging on tensile fatigue strength of bovine dentin. Dent Mater J 16(156-169):224

44. Kinney JH, Nalla RK, Pople JA, Breunig TM, Ritchie RO (2005) Age-related transparent root dentin: mineral concentration, crystallite size, and mechanical properties. Biomaterials 26:3363-3376

45. PradeepKumar AR, Shemesh H, Chang JW, Bhowmik A, Sibi S, Gopikrishna V, Lakshmi-Narayanan L, Kishen A (2017) Preexisting dentinal microcracks in nonendodontically treated teeth: an ex-vivo micro-computed tomographic analysis. J Endod 43:896-900

46. De-Deus G, Belladonna FG, Marins JR, Silva EJ, Neves AA, Souza EM, Machado AC, Lopes RT, Versiani MA (2016) On the causality between dentinal defects and root canal preparation: a micro-CT assessment. Braz Dent J 27:664-669

47. Liu R, Hou BX, Wesselink PR, Wu M-K, Shemesh H (2013) The incidence of root microcracks caused by 3 different single-file systems versus the ProTaper System. J Endod 39:1054-1056

48. Hassan B, Metska ME, Ozok AR, van der Stelt P, Wesselink PR (2009) Detection of vertical root fractures in endodontically treated teeth by a cone beam computed tomography scan. J Endod 35:719-722

49. Rainwater A, Jeansonne B, Sarkar N (2000) Effects of ultrasonic root-end preparation on microcrack formation and leakage. $\mathrm{J}$ Endod 26:72-75

50. Soni D, Raisingani D, Mathur R, Madan N, Visnoi S (2016) Incidence of apical crack initiation during canal preparation using hand stainless steel (K-File) and hand NiTi (ProTaper) files. Int J Clin Pediatr Dent 9:303-307

51. Shemesh H, Wesselink PR, Wu M-K (2010) Incidence of dentinal defects after root canal filling procedures. Int Endod $\mathrm{J}$ 43:995-1000

52. Shemesh H, Roeleveld AC, Wesselink PR, Wu M-K (2011) Damage to root dentin during retreatment procedures. J Endod 37:63-66

53. Layton CA, Marshall JG, Morgan LA, Baumgartner JC (1996) Evaluation of cracks associated with ultrasonic root-end preparation. J Endod 22:157-160

54. Beling KL, Marshall JG, Morgan LA, Baumgartner JC (1997) Evaluation for cracks associated with ultrasonic root-end preparation of gutta-percha filled canals. J Endod 23:323-326

55. Morgan LA, Marshall JG (1998) The topography of root ends resected with fissure burs and refined with two types of finishing burs. Oral Surg Oral Med Oral Pathol Oral Radiol Endod 85:585-591

56. Çapar İD, Gök T, Uysal B, Keleş A (2019) Comparison of microcomputed tomography, cone beam tomography, stereomicroscopy, and scanning electron microscopy techniques for detection of 
microcracks on root dentin and effect of different apical sizes on microcrack formation. Microsc Res Tech 82:1748-1755

57. Jamleh A, Adorno CG, Ebihara A, Suda H (2016) Effect of nickel titanium file design on the root surface strain and apical microcracks. Aust Endod J 42:25-31

58. Saber SM, Eshkal SEA, Nagy MM, Pirani C (2020) Correlation between root surface strain and apical micro-cracks produced during canal preparation with thermally treated single or multi-file NiTi systems. G Ital Endod 34:75-82

59. De Munck J, Van Landuyt K, Peumans M, Poitevin A, Lambrechts P, Braem M, Van Meerbeek B (2005) A critical review of the durability of adhesion to tooth tissue: methods and results. J Dent Res 84:118-132

60. Gondim E Jr, Gomes BP, Ferraz CC, Teixeira FB, Souza-Filho FJ (2002) Effect of sonic and ultrasonic retrograde cavity preparation on the integrity of root apices of freshly extracted human teeth: scanning electron microscopy analysis. J Endod 28:646-650

61. Queiroz PM, Rovaris K, Gaêta-Araujo H, de Souza M, Bueno S, Freitas DQ, Groppo FC, Haiter-Neto F (2017) Influence of artifact reduction tools in micro-computed tomography images for endodontic research. J Endod 43:2108-2111

62. Celikten B, Jacobs R, de Faria VK, Huang Y, Shaheen E, Nicolielo LFP, Orhan K (2019) Comparative evaluation of cone beam $\mathrm{CT}$ and micro-CT on blooming artifacts in human teeth filled with bioceramic sealers. Clin Oral Investig 23:3267-3273

63. Jung M, Lommel D, Klimek J (2005) The imaging of root canal obturation using micro-CT. Int Endod J 38:617-626

64. Kierklo A, Tabor Z, Pawińska M, Jaworska M (2015) A microcomputed tomography-based comparison of root canal filling quality following different instrumentation and obturation techniques. Med Princ Pract 24:84-91

65. Van de Casteele E, Van Dyck D, Sijbers J, Raman E (2004) The effect of beam hardening on resolution in X-ray microtomography. Medical Imaging 2004: Image Processing. International Society for Optics and Photonics
66. Blum JY, Machtou P, Ruddle C, Micallef JP (2003) Analysis of mechanical preparations in extracted teeth using ProTaper rotary instruments: value of the safety quotient. J Endod 29:567-575

67. Bürklein S, Stüber JP, Schäfer E (2019) Real-time dynamic torque values and axial forces during preparation of straight root canals using three different endodontic motors and hand preparation. Int Endod J 52:94-104

68. El Nasr HMA, El Kader KGA (2014) Dentinal damage and fracture resistance of oval roots prepared with single-file systems using different kinematics. J Endod 40:849-851

69. Adl A, Sedigh-Shams M, Majd M (2015) The effect of using RC prep during root canal preparation on the incidence of dentinal defects. J Endod 41:376-379

70. Shen Y, Zhou HM, Zheng YF, Peng B, Haapasalo M (2013) Current challenges and concepts of the thermomechanical treatment of nickel-titanium instruments. J Endod 39:163-172

71. Priya NT, Chandrasekhar V, Anita S, Tummala M, Raj TB, Badami V, Kumar P, Soujanya E (2014) "Dentinal microcracks after root canal preparation" a comparative evaluation with hand, rotary and reciprocating instrumentation. J Clin Diagn Res 8:Zc70-72

72. Harandi A, Mirzaeerad S, Mehrabani M, Mahmoudi E, Bijani A (2017) Incidence of dentinal crack after root canal preparation by ProTaper Universal, Neolix and SafeSider systems. Iran Endod J 12:432-438

73. Shantiaee Y, Dianat O, Mosayebi G, Namdari M, Tordik P (2019) Effect of root canal preparation techniques on crack formation in root dentin. J Endod 45:447-452

Publisher's Note Springer Nature remains neutral with regard to jurisdictional claims in published maps and institutional affiliations. 